\title{
Prognostic value of clinically important deterioration in COPD: IMPACT trial analysis
}

\author{
MeiLan K. Han ${ }^{1}$, Gerard J. Criner ${ }^{2}$, Mark T. Dransfield ${ }^{3}$, David M.G. Halpin ${ }^{4}$, \\ Christine E. Jones ${ }^{5}$, Sally Kilbride ${ }^{6}$, Peter Lange ${ }^{7,8}$, Sally Lettis ${ }^{6}$, \\ David A. Lipson (10,10, David A. Lomas ${ }^{11}$, Neil Martin ${ }^{12,13}$, \\ Fernando J. Martinez ${ }^{14}$, Robert A. Wise ${ }^{15}$, Ian P. Naya ${ }^{12,17}$ and Dave Singh ${ }^{16,17}$
}

\section{ABSTRACT}

Introduction: Clinically important deterioration (CID) is a multicomponent measure for assessing disease worsening in chronic obstructive pulmonary disease (COPD). This analysis investigated the prognostic value of a CID event on future clinical outcomes and the effect of single-inhaler triple versus dual therapy on reducing CID risk in patients in the IMPACT trial.

Methods: IMPACT was a phase III, double-blind, 52-week, multicentre trial. Patients with symptomatic COPD and at least one moderate/severe exacerbation in the prior year were randomised 2:2:1 to fluticasone furoate/umeclidinium/vilanterol (FF/UMEC/VI) 100/62.5/25 $\mu \mathrm{g}$, FF/VI 100/25 $\mu \mathrm{g}$ or UMEC/VI $62.5 / 25 \mu \mathrm{g}$. CID at the time-point of interest was defined as a moderate/severe exacerbation, $\geqslant 100 \mathrm{~mL}$ decrease in trough forced expiratory volume in $1 \mathrm{~s}$ or deterioration in health status (increase of $\geqslant 4.0$ units in St George's Respiratory Questionnaire total score or increase of $\geqslant 2.0$ units in COPD Assessment Test score) from baseline. A treatment-independent post hoc prognostic analysis compared clinical outcomes up to week 52 in patients with/without a CID by week 28 . A prospective analysis evaluated time to first CID with each treatment.

Results: Patients with a CID by week 28 had significantly increased exacerbation rates after week 28, smaller improvements in lung function and health status at week 52 (all $\mathrm{p}<0.001$ ), and increased risk of all-cause mortality after week 28 versus patients who were CID-free. FF/UMEC/VI significantly reduced CID risk versus dual therapies (all $\mathrm{p}<0.001$ ).

Conclusions: Prevention of short-term disease worsening was associated with better long-term clinical outcomes. FF/UMEC/VI reduced CID risk versus dual therapies; this effect may improve long-term prognosis in this population.

@ERSpublications

Preventing short-term clinically important deterioration (CID) is associated with better longterm clinical outcomes in patients with COPD. FF/UMEC/VI reduces CID risk versus FF/VI and $\mathrm{UMEC} / \mathrm{VI}$ therapy, and this may improve patients' long-term prognosis. https://bit.ly/3gP1KJu

Cite this article as: Han MK, Criner GJ, Dransfield MT, et al. Prognostic value of clinically important deterioration in COPD: IMPACT trial analysis. ERJ Open Res 2021; 7: 00663-2020 [https://doi.org/10.1183/23120541.00663-2020].

This article has supplementary material available from openres.ersjournals.com

This study is registered at www.clinicaltrials.gov with identifier number NCT02164513. Anonymised individual participant data and study documents can be requested for further research from www.clinicalstudydatarequest.com

Received: 26 Nov 2020 | Accepted after revision: 8 Dec 2020

Copyright $\odot$ ERS 2021. This article is open access and distributed under the terms of the Creative Commons Attribution Non-Commercial Licence 4.0. 


\section{Introduction}

Chronic obstructive pulmonary disease (COPD) is a heterogeneous and frequently progressive disease. The Global Initiative for Chronic Obstructive Lung Disease (GOLD) 2019 report advocates routine monitoring of disease progression using measurements of change in an individual's symptoms, exacerbation risk and lung function $[1,2]$.

Clinically important deterioration (CID) is a multicomponent measure of worsening COPD that mirrors these recommendations to assess suboptimal treatment responses and disease instability using widely accepted thresholds of change in lung function and/or health status or a first acute moderate-to-severe COPD exacerbation as a measure of important deterioration [3]. Post hoc analyses have consistently shown that short-term worsening identified by these three individual CID measures can be reduced through treatment escalation with long-acting bronchodilator versus placebo, dual bronchodilator versus monotherapy, or triple therapy versus inhaled corticosteroid (ICS)/long-acting $\beta_{2}$-agonist (LABA) or long-acting muscarinic antagonist (LAMA)/LABA therapy [3-7]. These positive findings for intensification of bronchodilation have also been confirmed prospectively with triple therapy versus ICS/LABA [5] and LAMA/LABA versus LAMA or LABA monotherapy [8].

Preventing short-term CID events (defined by worsening in lung function, health status or exacerbations) has also been associated with sustained treatment benefits $[5,9]$, and a reduced risk of all-cause mortality in up to 3 years of follow-up in the ECLIPSE and TORCH studies [9]. In TORCH, all CID components contributed to mortality risk and freedom from all event types was associated with the greatest survival benefit [9]. In the UPLIFT study patients with a CID were more likely to experience subsequent exacerbation and death [6]. However, data in COPD populations at high exacerbation risk are needed to further understand the contribution of each component to clinical outcomes.

Recently, the InforMing the PAthway of COPD Treatment (IMPACT) trial demonstrated that single-inhaler triple therapy fluticasone furoate/umeclidinium/vilanterol (FF/UMEC/VI) significantly reduced moderate/severe exacerbation rates versus FF/VI or UMEC/VI, and significantly reduced severe exacerbation rates and all-cause mortality versus UMEC/VI in symptomatic COPD patients with a history of exacerbations [10]. Based on 1-year data from IMPACT, we conducted a treatment-independent post hoc analysis of the prognostic value of a CID event (deterioration on any of the CID components) within the first 28 weeks on moderate/severe exacerbation occurrence and mortality risk after week 28 , and worsening of lung function and health status over 52 weeks. Additional analyses included the effect of FF/UMEC/VI versus FF/VI and UMEC/VI on reducing the risk of a first CID.

\section{Methods}

Study design

IMPACT (European Union Clinical Trials Register: CTT116855 and ClinicalTrials.gov: NCT02164513) was a phase III, double-blind, parallel-group, 52-week, multicentre study in patients $\geqslant 40$ years of age with symptomatic COPD and at least one moderate/severe exacerbation in the prior year. Patients were randomised 2:2:1 to FF/UMEC/VI 100/62.5/25 $\mu \mathrm{g}$, FF/VI 100/25 $\mu \mathrm{g}$ or UMEC/VI 62.5/25 $\mu \mathrm{g}$ once daily via a single dry-power inhaler (ELLIPTA; GlaxoSmithKline, Brentford, UK) [10]. The study design and primary results have been previously published [10].

\section{End-points}

CID was defined as any of the following on-treatment events: moderate/severe exacerbation, deterioration in lung function $\left(\geqslant 100 \mathrm{~mL}\right.$ decrease from baseline in trough forced expiratory volume in $\left.1 \mathrm{~s}\left(\mathrm{FEV}_{1}\right)[11]\right)$

\footnotetext{
Affiliations: ${ }^{1}$ Division of Pulmonary and Critical Care Medicine, University of Michigan, Ann Arbor, MI, USA. ${ }^{2}$ Lewis Katz School of Medicine, Temple University, Philadelphia, PA, USA. ${ }^{3}$ Lung Health Center, Division of Pulmonary, Allergy and Critical Care Medicine, University of Alabama at Birmingham, Birmingham, AL, USA. ${ }^{4}$ Medical School, College of Medicine and Health, University of Exeter, Exeter, UK. ${ }^{5}$ GSK, Research Triangle Park, NC, USA. ${ }^{6}$ GSK, Uxbridge, UK. ${ }^{7}$ Section of Epidemiology, Dept of Public Health, University of Copenhagen, Copenhagen, Denmark. ${ }^{8}$ Medical Dept, Herlev Gentofte Hospital, Herlev, Denmark. ${ }^{9}$ GSK, Collegeville, PA, USA. ${ }^{10}$ Pulmonary, Allergy and Critical Care Division, Perelman School of Medicine, University of Pennsylvania, Philadelphia, PA, USA. ${ }^{11}$ UCL Respiratory, University College London, London, UK. ${ }^{12}$ GSK, Brentford, UK. ${ }^{13}$ Institute for Lung Health, University of Leicester, Leicester, UK. ${ }^{14}$ NewYorkPresbyterian/Weill Cornell Medicine, New York, NY, USA. ${ }^{15}$ Division of Pulmonary and Critical Care Medicine, Johns Hopkins University School of Medicine, Baltimore, MD, USA. ${ }^{16}$ Centre for Respiratory Medicine and Allergy, Institute of Inflammation and Repair, Manchester Academic Health Science Centre, University of Manchester, Manchester University NHS Foundation Trust, Manchester, UK. ${ }^{17}$ These authors contributed equally.
}

Correspondence: MeiLan K. Han, Division of Pulmonary and Critical Care Medicine, University of Michigan, 1500 E. Medical Center Drive, Ann Arbor, MI 48109, USA. E-mail: mrkingđuumich.edu 
or deterioration in health status (increase from baseline of $\geqslant 4.0$ units in St George's Respiratory Questionnaire (SGRQ) total score [11] or $\geqslant 2.0$ units in COPD Assessment Test (CAT) score [12]) (table 1). Moderate exacerbations were those requiring treatment with antibiotics and/or oral/systemic corticosteroids; severe exacerbations were those resulting in hospitalisation or death.

The post hoc prognostic analysis, independent of treatment, investigated whether short-term worsening by week 28 in any component (CID-positive), compared with freedom from all worsening types (CID-negative), led to worse longer-term outcomes. Outcomes of interest included annual moderate/severe or severe exacerbation rates, time to first moderate/severe or severe exacerbation and all-cause mortality during weeks 29-52, and change from baseline in trough $\mathrm{FEV}_{1}$, SGRQ total score and CAT score at week 52.

All-cause mortality incorporated on- and off-treatment deaths, and included $99.6 \%$ of the study population's vital status at week 52. On- and off-treatment deaths were those that occurred between study treatment start and 7 days after stopping study treatment (inclusive) for patients who completed the study or up to the projected week 52 date plus 7 days for patients who prematurely discontinued study treatment. As the IMPACT trial was enriched for a population at risk of exacerbations, the effect of CID status by week 28 on all-cause mortality was also examined using a single-component definition based solely on first moderate/severe exacerbation; this was compared with the full three-component CID definitions (using either SGRQ total score $\left(\mathrm{CID}^{\mathrm{SGRQ}}\right.$ ) or CAT score (CID ${ }^{\mathrm{CAT}}$ ) for assessing health status) (table 1) and two-component definitions that excluded exacerbations to understand the relative importance of exacerbation events in the composite definitions.

The prospective analysis evaluated between-treatment comparisons of CID risk (time to first event) with FF/UMEC/VI versus FF/VI and UMEC/VI at weeks 28 and 52. Pre-specified subgroup analyses assessed treatment effect on $\mathrm{CID}^{\mathrm{SGRQ}}$ and $\mathrm{CID}^{\mathrm{CAT}}$ risk by baseline CAT score $(<20$ or $\geqslant 20$ units) [1], baseline medication use, baseline ICS use, smoking status, age, body mass index and sex. Post hoc subgroup analyses by exacerbation history in the prior year $(<2$ or $\geqslant 2$ moderate/severe and 0 or $\geqslant 1$ severe) and blood eosinophil count $\left(<150\right.$ or $\geqslant 150$ cells $\left.\mu \mathrm{L}^{-1}\right)$ were also conducted. A further post hoc analysis evaluated the risk of $\mathrm{CID}^{\mathrm{SGRQ}}, \mathrm{CID}^{\mathrm{CAT}}$ or any $\mathrm{CID}$ component by continuous baseline eosinophil counts. Statistical analyses were performed using SAS version 9.3 (SAS Institute, Cary, NC, USA) and are described in the supplementary material. No imputations for missing data were performed.

\section{Results}

Patients

The IMPACT intent-to-treat population included 10355 patients (FF/UMEC/VI n=4151; FF/VI n=4134; UMEC/VI n=2070). Baseline demographics and clinical characteristics were similar between treatment arms (table 2).

\section{Nontreatment-related prognostic outcomes by CID status by week 28}

Using the $\mathrm{CID}^{\mathrm{SGRQ}}$ definition, CID-positive patients by week 28 had a $75 \%$ increase in annual moderate/severe exacerbation rate (rate ratio (RR) 1.75 (95\% CI 1.60-1.92); $<<0.001)$ and a $96 \%$ increase in severe exacerbation rate

\section{TABLE 1 Clinically important deterioration (CID) and mortality sensitivity analysis definitions used in this analysis}

\section{CID component}

Exacerbation Lung function Health status

\section{Composite CID definitions $\mathrm{CID}^{\mathrm{SGRQ}}$ \\ CID ${ }^{\text {CAT }}$}

\section{Mortality sensitivity analysis} definitions

Two-component including SGRQ

Two-component including CAT

Single-component including exacerbation only
Moderate/severe exacerbation

Moderate/severe exacerbation

\section{Moderate/severe exacerbation}

$\geqslant 4.0$ unit increase from baseline in SGRQ total score
$\geqslant 2.0$ unit increase from baseline in CAT score trough $\mathrm{FEV}_{1}$

$\geqslant 100 \mathrm{~mL}$ decrease from baseline in trough FEV

SGRQ: St George's Respiratory Questionnaire; CAT: COPD Assessment Test; COPD: chronic obstructive pulmonary disease; FEV ${ }_{1}$ : forced expiratory volume in $1 \mathrm{~s}$. 


\begin{tabular}{|c|c|c|c|}
\hline & FF/UMEC/VI & FF/VI & UMEC/VI \\
\hline Subjects & 4151 & 4134 & 2070 \\
\hline Age years & $65.3 \pm 8.2$ & $65.3 \pm 8.3$ & $65.2 \pm 8.3$ \\
\hline Male & 2766 (67) & $2748(66)$ & $1356(66)$ \\
\hline BMI $\mathrm{kg} \cdot \mathrm{m}^{-2}$ & $26.6 \pm 6.2$ & $26.7 \pm 6.1$ & $26.6 \pm 5.9$ \\
\hline \multicolumn{4}{|l|}{ Smoking status } \\
\hline Current smoker & 1436 (35) & $1423(34)$ & 728 (35) \\
\hline Ex-smoker & $2715(65)$ & $2711(66)$ & 1342 (65) \\
\hline \multicolumn{4}{|l|}{ Exacerbation history in prior year } \\
\hline 1 moderate and 0 severe & $1198(29)$ & $1242(30)$ & $616(30)$ \\
\hline$\geqslant 2$ moderate or $\geqslant 1$ severe & $2953(71)$ & $2892(70)$ & $1454(70)$ \\
\hline Pre-bronchodilator $\mathrm{FEV}_{1} \mathrm{~mL}$ & $1170 \pm 468$ & $1163 \pm 468$ & $1167 \pm 464$ \\
\hline Pre-bronchodilator FEV $1 \%$ pred & $41.9 \pm 14.6$ & $41.6 \pm 14.5$ & $41.8 \pm 14.4$ \\
\hline Post-bronchodilator FEV 1 mL & $1275 \pm 488$ & $1272 \pm 486$ & $1268 \pm 481$ \\
\hline Post-bronchodilator FEV $1 \%$ pred & $45.7 \pm 15.0$ & $45.5 \pm 14.8$ & $45.4 \pm 14.7$ \\
\hline SGRQ total score & $50.8 \pm 16.8$ & $50.7 \pm 17.0$ & $50.2 \pm 16.7$ \\
\hline CAT score & $20.1 \pm 6.1$ & $20.1 \pm 6.1$ & $20.2 \pm 6.2$ \\
\hline Blood eosinophil count cells. $\mu \mathrm{L}^{-1}$ & $219 \pm 232$ & $223 \pm 239$ & $227 \pm 226$ \\
\hline \multicolumn{4}{|l|}{ COPD medication ${ }^{\#}$} \\
\hline ICS+LABA+LAMA & $1672(40)$ & $1647(40)$ & 864 (42) \\
\hline ICS+LABA & 1354 (33) & 1340 (32) & 647 (31) \\
\hline$L A M A+L A B A$ & 389 (9) & $349(8)$ & $196(9)$ \\
\hline LAMA & $304(7)$ & $365(9)$ & $162(8)$ \\
\hline \multicolumn{4}{|c|}{$\begin{array}{l}\text { Data are presented as } \mathrm{n}, \text { mean } \pm \text { SD or } \mathrm{n}(\%) \text {. FF: fluticasone furoate; UMEC: umeclidinium; VI: vilanterol; } \\
\text { BMI: body mass index; FEV }{ }_{1} \text { : forced expiratory volume in } 1 \mathrm{~s} \text {; SGRQ: St George's Respiratory } \\
\text { Questionnaire; CAT: COPD Assessment Test; COPD: chronic obstructive pulmonary disease; ICS: inhaled } \\
\text { corticosteroid; LABA: long-acting } \beta_{2} \text {-agonist; LAMA: long-acting muscarinic antagonist. " } \text { : in the } 3 \text { days } \\
\text { prior to and including screening (post hoc analysis). }\end{array}$} \\
\hline
\end{tabular}

(RR 1.96 (95\% CI 1.56-2.47); p<0.001) over weeks 29-52 versus CID-negative patients (table 3). Significant improvements in trough $\mathrm{FEV}_{1}$ (difference $143 \mathrm{~mL}$ ) and health status (SGRQ difference -7.5 units; CAT difference -2.1 units) at week 52 were seen in the CID-negative versus CID-positive subgroups (all $\mathrm{p}<0.001$ ) (table 3 ).

Similar results were seen using the $\mathrm{CID}^{\mathrm{CAT}}$ definition. Compared with CID-negative patients, by week 28 , CID-positive patients had a 72\% increase (RR 1.72 (95\% CI 1.56-1.89); p<0.001) and 91\% increase (RR 1.91 (95\% CI 1.50-2.42); $\mathrm{p}<0.001)$ in the rate of moderate/severe and severe exacerbations, respectively, over weeks 29-52. Furthermore, CID-negative patients demonstrated improvements in week $52 \mathrm{FEV}_{1}$ (difference $142 \mathrm{~mL}$ ) and health status (SGRQ difference -5.4 units; CAT difference -3.2 units) versus CID-positive patients (all $\mathrm{p}<0.001$ ) (table 3).

Kaplan-Meier survival analysis indicated that CID-positive patients by week 28 (using CID $^{\text {SGRQ }}$ and CID $^{\text {CAT }}$ definitions) had a numerically higher mortality risk over weeks 29-52 compared with CID-negative patients $\left(55 \%\right.$ increased risk $(p=0.069)$ for CID $^{\text {SGRQ }}$ and $80 \%$ increased risk $(p=0.025)$ for $\mathrm{CID}^{\mathrm{CAT}}$ (Cox proportional hazard model)) (figure 1a and b and supplementary figure E1). The prognostic findings appeared to highlight increasing differences in mortality accumulated month-by-month of the follow-up period in the CID-positive versus CID-negative subgroups (figure 1).

In the sensitivity analysis, single-component CID assessed by exacerbation status alone at week 28 showed no separation in mortality risk during weeks 29-52 ( $\mathrm{p}=0.402$ (Cox proportional hazard model)) (figure 1c). Hazard ratio point estimates for CID-positive versus CID-negative patients for all-cause mortality were higher using the $\mathrm{CID}^{\mathrm{SGRQ}}$ and $\mathrm{CID}^{\mathrm{CAT}}$ definitions compared with two-component definitions (excluding exacerbations), and were lowest when using moderate/severe exacerbation only as a prognostic marker of short-term CID (supplementary figure E1).

\section{Effects of treatment on the incidence and risk (time to first) of CID}

Using the $\mathrm{CID}^{\mathrm{SGRQ}}$ definition, the proportion of patients experiencing a CID was between $62 \%$ and $83 \%$ for all treatments by week 28 and 52, with a lower incidence seen with FF/UMEC/VI versus FF/VI or UMEC/VI (figure 2 and supplementary table E1). Results were similar for the CID $^{\text {CAT }}$ definition, with between $67 \%$ and $85 \%$ of patients experiencing a composite CID for all treatments by week 28 and 52 . 
TABLE 3 Outcomes post-week 28 by clinically important deterioration (CID) status at week 28 (definition including St George's Respiratory Questionnaire (SGRQ) or COPD Assessment Test (CAT))

\section{CID-positive}

CID-negative

\section{Definition including SGRQ}

Rate of exacerbations

Moderate/severe exacerbations after week 28

Severe exacerbations after week 28

Time to first exacerbation

Moderate/severe exacerbations after week 28

Severe exacerbations after week 28

Time to all-cause mortality

All-cause mortality after week $28^{\# \#}$

Trough $\mathrm{FEV}_{1}$ at week $52 \mathrm{~mL}$

SGRQ total score at week 52

CAT score at week 52

\section{Definition including CAT}

Rate of exacerbations

Moderate/severe exacerbations after week 28

Severe exacerbations after week 28

Time to first exacerbation

Moderate/severe exacerbations after week 28

Severe exacerbations after week 28

Time to all-cause mortality

All-cause mortality after week $28^{\# \#}$

Trough $\mathrm{FEV}_{1}$ at week $52 \mathrm{~mL}$

SGRQ total score at week 52

CAT score at week 52
$\mathrm{N}=3055^{\#}$

$\begin{array}{cc}\mathrm{N}=7008^{\#} & \mathrm{~N}=3055^{\#} \\ \substack{\text { Annual rates } \\(95 \% \mathrm{Cl})} \\ \mathrm{n}=5860^{\mathrm{f}_{1}+} & \mathrm{n}=2729^{\mathrm{\eta},+} \\ 0.94(0.90-0.98) & 0.54(0.49-0.58) \\ 0.14(0.12-0.16) & 0.07(0.06-0.09)\end{array}$

Patients with event (\%)

$\begin{array}{cc}\mathrm{n}=5864^{1,+, f} & \mathrm{n}=2732^{\uparrow 1,+, f} \\ 1900(32) & 548(20) \\ 391(7) & 99(4) \\ \mathrm{n}=5887 & \mathrm{n}=2732 \\ 77(1) & 23(<1)\end{array}$

LS mean CFB $(95 \% \mathrm{CI})$

$n=5359$

9 (2-15)

$\mathrm{n}=5298$

$-2.4(-2.7--2.0)$

$\mathrm{n}=5218$

$-1.2(-1.3--1.0)$

$\mathrm{N}=7304^{\#}$

Annual rates $(95 \% \mathrm{CI})$

$\mathrm{n}=6150^{\mathrm{n},++}$

$0.92(0.88-0.96)$

$-3.3(-3.5--3.0)$

$\mathrm{N}=2759^{\#}$

2 (143-162)

$\mathrm{n}=2516$

$9.8(-10.3--9.3)$

(10.3
$0.15(0.13-0.17)$

$\mathrm{n}=5632$

LS mean CFB $(95 \% \mathrm{CI})$

14 (7-20)

$\mathrm{n}=2284$

$\mathrm{n}=5565$

$156(146-167)$

$n=2249$

$-3.2(-3.6--2.9)$

$\mathrm{n}=5502$

$-8.6(-9.2--8.0)$

$\mathrm{n}=2198$
Difference (CID-positive versus CID-negative]

$\%$ increase in rate $(95 \% \mathrm{CI})$

$75(60-92)^{\S}$

$96(56-147)^{\S}$

$\%$ increase in risk $(95 \% \mathrm{CI})$

$$
72(56-89)^{\S}
$$

$79(43-123)^{\S}$

$55(-3-147)^{19}$

Difference $(95 \% \mathrm{CI})$

$-143(-155--132)^{\S}$

$7.5(6.8-8.1)^{\S}$

$2.1(1.8-2.4)^{\S}$

$\%$ increase in rate $(95 \% \mathrm{Cl})$

$72(56-89)^{\S}$

$91(50-142)^{\S}$

$\%$ increase in risk $(95 \% \mathrm{CI})$

$68(52-86)^{\S}$

$78(41-125)^{\S}$

$80(8-200)^{\S \S}$

\section{Difference $(95 \% \mathrm{Cl})$}

$-0.9(-1.1--0.8)$

$-4.1(-4.4--3.9)$

$-142(-155--130)^{\S}$

$5.4(4.7-6.0)^{\S}$

$3.2(2.9-3.5)^{\S}$

COPD: chronic obstructive pulmonary disease; N: number of patients with CID status available at week 28; LS: least squares; CFB: change from baseline; $\mathrm{FEV}_{1}$ : forced expiratory volume in $1 \mathrm{~s}$. \#: number of patients who deteriorated on any of the CID components up to week 28 (CID-positive) or who did not deteriorate on any of the CID components up to week 28 (CID-negative) (if a patient has all missing on-treatment assessments for an end-point (trough FEV $1, \mathrm{SGRQ}$ and CAT) up to the time-point of interest, CID status was considered as missing for that patient, end-point and time-point); ${ }^{\natural}$ : excludes those patients who discontinued prior to week $28 ;{ }^{+}$: seven patients were excluded from the analysis due to missing covariates (CID-positive $n=4 ; C I D$-negative $n=3$ ); ${ }^{\S}: p<0.001 ;{ }^{f}$ : number of patients included in the Kaplan-Meier estimates; ${ }^{\# \#}$ : post hoc analysis of all-cause mortality including off-treatment data following additional collection of vital status (providing data for $99.6 \%$ of the IMPACT trial population); ${ }^{\text {१ी: }}$ p $>0.05 ;{ }^{++}$: seven patients were excluded from the analysis due to missing covariates (CID-positive: $n=3$; CID-negative: $n=4)$; ${ }^{\S}: p<0.05$. Positive differences in CAT score $\geqslant 2$ units or $S G R Q$ total score $\geqslant 4$ units and negative differences in trough $\mathrm{FEV}_{1} \geqslant 100 \mathrm{~mL}$ in magnitude indicate sustained clinically important worsening between the CID-positive and CID-negative subgroups (difference in change from baseline greater than the corresponding minimal clinically important differences [11, 12, 26]).

Kaplan-Meier plots of time to first CID event using CID $^{\text {SGRQ }}$ or CID $^{\text {CAT }}$ showed early separation in favour of FF/UMEC/VI versus both dual therapies (figure 3). This trend was also seen with each individual CID component (supplementary figure E2).

Using the $\mathrm{CID}^{\mathrm{SGRQ}}$ definition, $\mathrm{FF} / \mathrm{UMEC} / \mathrm{VI}$ significantly reduced CID risk by $33 \%$ and $31 \%$ by week 28 and 52 , respectively, versus FF/VI, and $26 \%$ and $24 \%$, respectively, versus UMEC/VI (all $\mathrm{p}<0.001$ ) (figures 2 


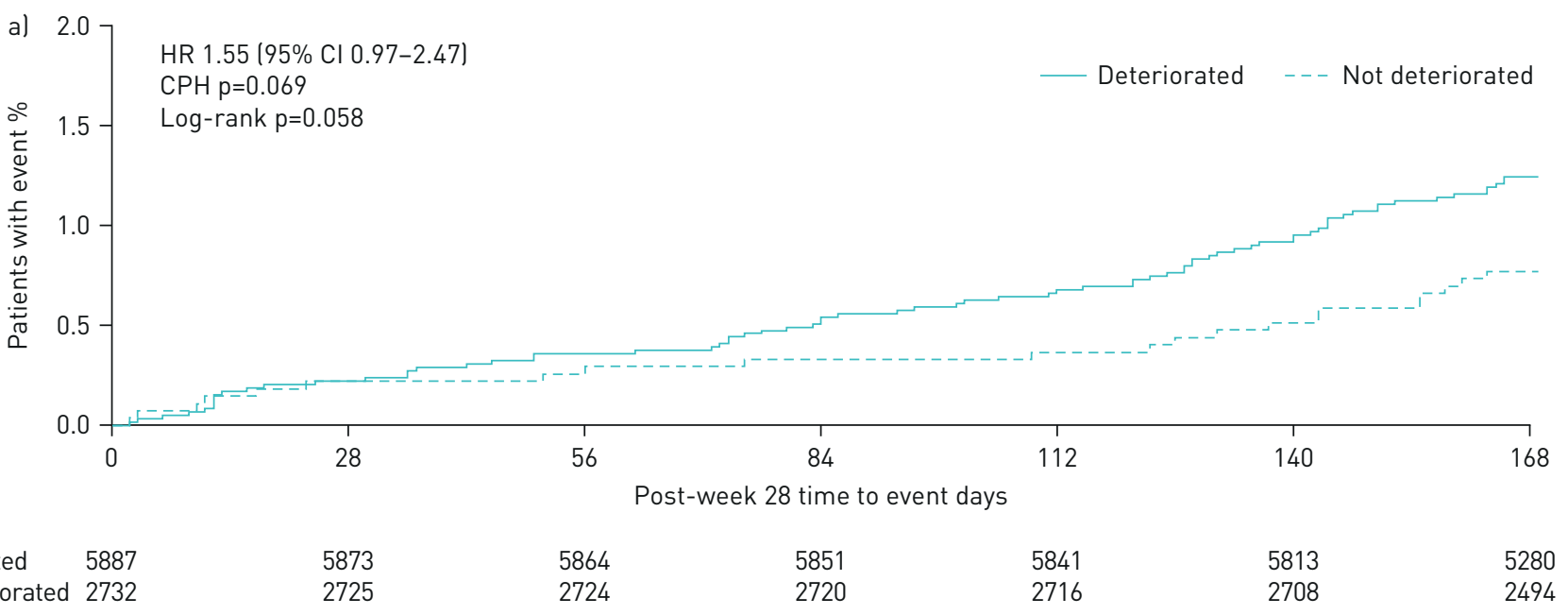

At risk $\mathrm{n}$ :

Deteriorated

$2725 \quad 2724$

2720

2716

2494

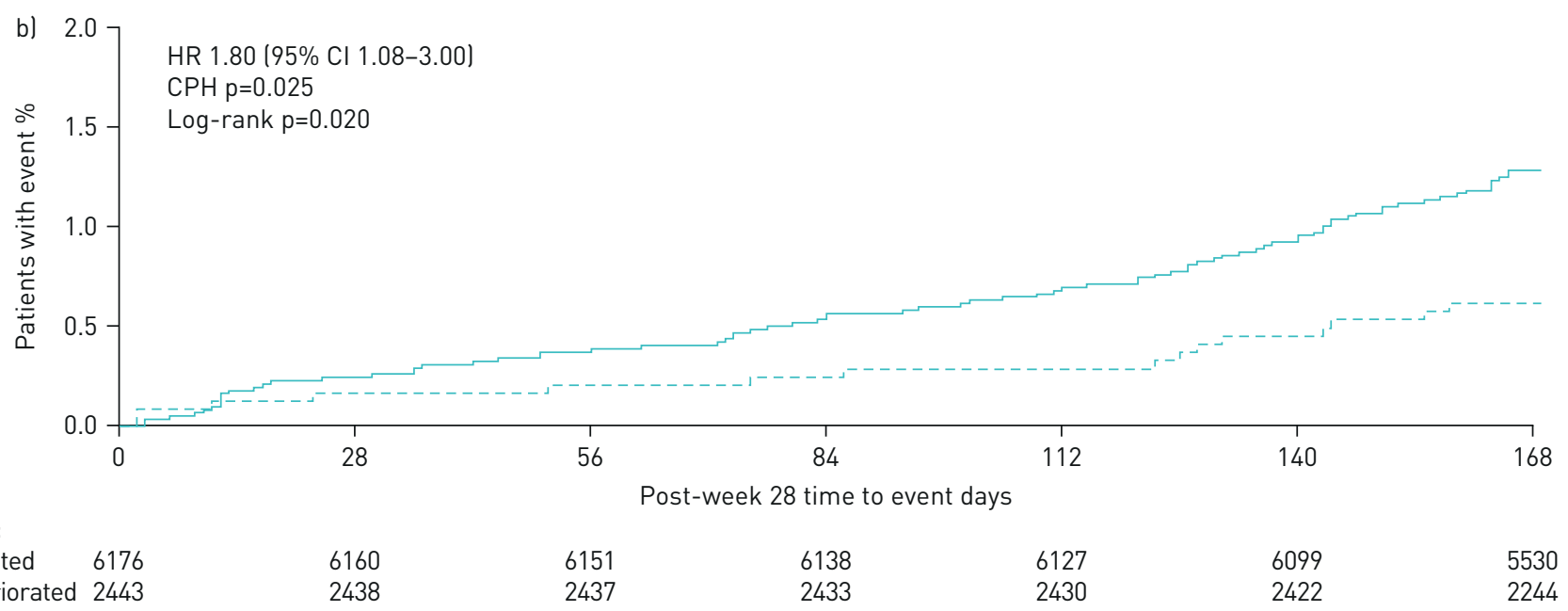

At risk $\mathrm{n}$ :

Deteriorated 6176

Nondeteriorated 2443

$2438 \quad 2437$

2433

2430

2244

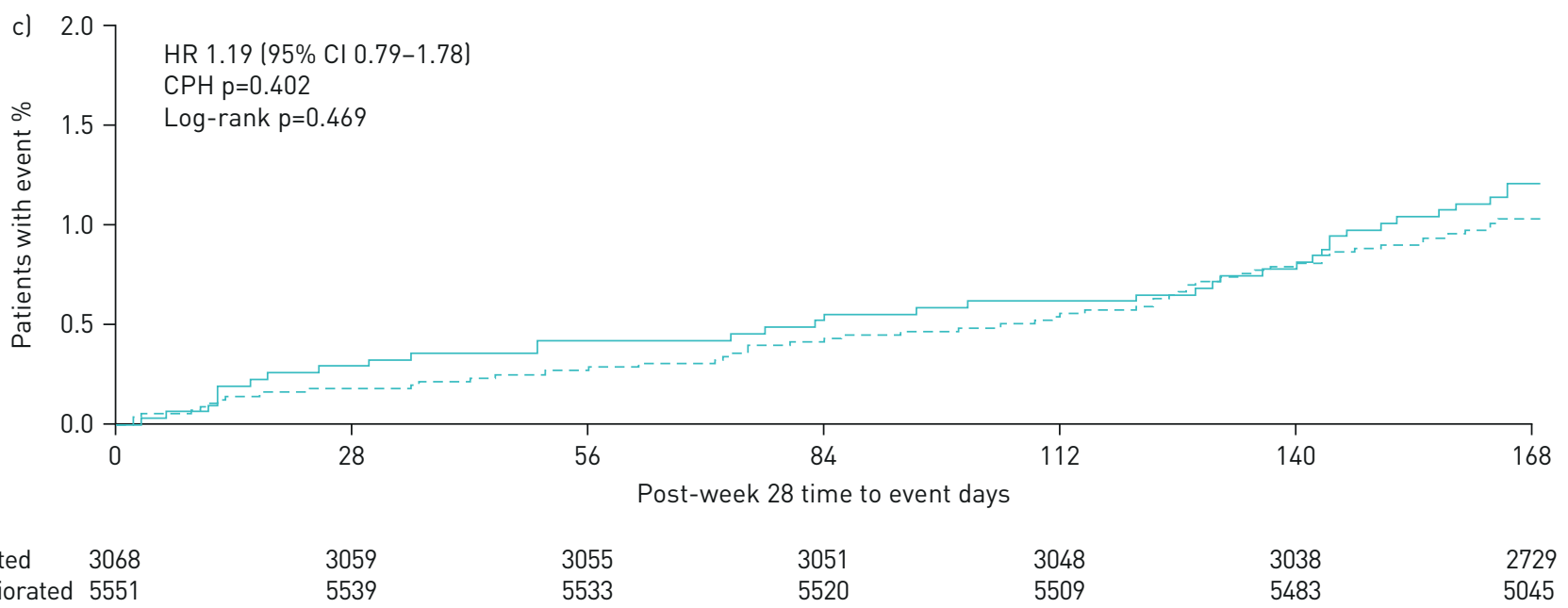

At risk $\mathrm{n}$

Deteriorated 3068

5539

5533

5520

5509

5483

5045

FIGURE 1 Kaplan-Meier plots of time to on-/off-treatment all-cause mortality post-week 28 by clinically important deterioration (CID) or exacerbation status at week 28 using a) the three-component definition using the St George's Respiratory Questionnaire (CID ${ }^{\text {SGRQ}}$ ), b) the three-component definition using the COPD Assessment Test (CID ${ }^{\mathrm{CAT}}$ ) and c) moderate/severe exacerbation only. COPD: chronic obstructive pulmonary disease; HR: hazard ratio; $\mathrm{CPH}$ : Cox proportional hazard model. Post hoc analysis of all-cause mortality including off-treatment data following additional collection of vital status (providing data for $99.6 \%$ of the IMPACT trial population). 
a)

Overall composite worsening CIDSGRQ

CIDCAT

Trough $\mathrm{FEV}_{1}$ worsening\#

Health status worsening SGRQ?

$\mathrm{CAT}^{+}$

Moderate/severe exacerbation

Overall composite worsening CIDSGRQ

CIDCAT

Trough FEV ${ }_{1}$ worsening\#

Health status worsening SGRQ?

$\mathrm{CAT}^{+}$

Moderate/severe exacerbation
Patients with events $\mathrm{n} / \mathrm{N}(\%)$

Favours Favours

FF/VI FF/UMEC/VI

FF/UMEC/VI FF/VI

$2545 / 4074$ (62)

$3011 / 4074$ (74)

2723/4074 (67)

$3143 / 4074$ (77)

$943 / 4017$ (23)

1238/4017 (31)

1258/3987 (32)

1497/3987 (38)

1549/3946 (39)

$1827 / 3951$ (46)

1447/4151 (35)

1959/4151 (47)

$F F / V I$
$3005 / 3984$ (75)
$3312 / 3984$ (83)
$3085 / 3984$ (77)
$3379 / 3984$ (85)
$1724 / 3896$ (44)
$1887 / 3896$ (48)
$1476 / 3868$ (38)
$1701 / 3870$ (44)
$1644 / 3819$ (43)
$1884 / 3821$ (49)
$1616 / 4134$ (39)
$2039 / 4134$ (49)

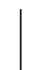

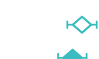

$\diamond$

$\diamond$ Week $28 \diamond$ Week 52

$33(29-36)$

$31(27-34)$

28 (24-32)

$27(23-30)$

$\diamond$

56 (52-59)

$52(49-55)$

$22(16-28)$

$22(16-27)$

$13(7-19)$

$13(7-18)$

$19(14-25)$

$15(9-20)$

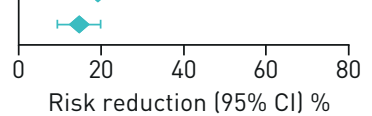

Risk reduction $(95 \% \mathrm{CI}) \%$

Favours Favours

UMEC/VI FF/UMEC/VI

Patients with events $\mathrm{n} / \mathrm{N}(\%)$

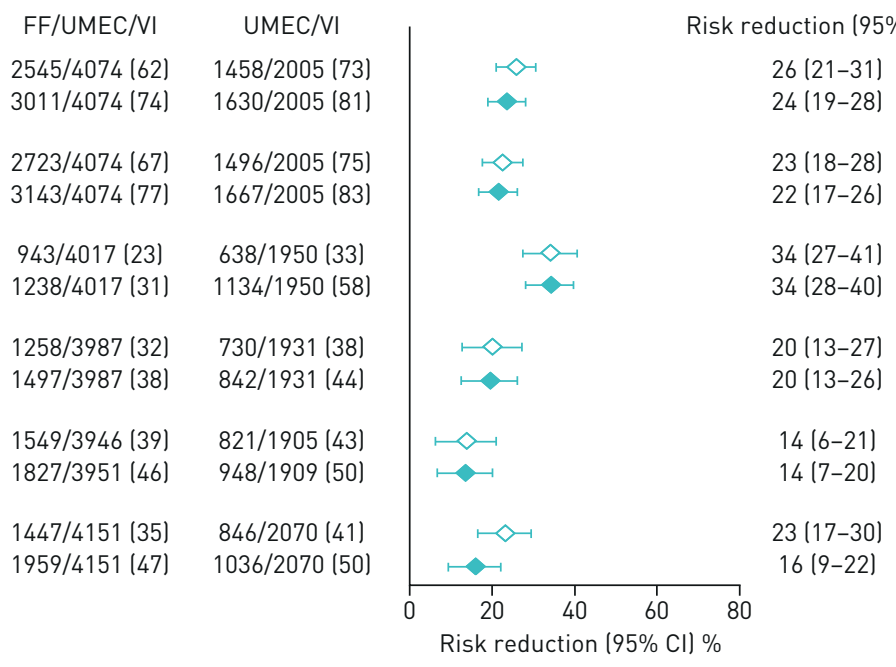

FIGURE 2 Reduction in clinically important deterioration (CID) risk (time to first) with fluticasone furoate/ umeclidinium/vilanterol (FF/UMEC/VI) versus a) FF/VI and b) UMEC/VI. $\mathrm{n}$ : number of patients with events; $\mathrm{N}$ : number of patients with analysable data; $C D^{S G R Q}$ : three-component definition using the St George's Respiratory Questionnaire; CID ${ }^{\text {CAT }}$ : three-component definition using the COPD Assessment Test; COPD: chronic obstructive pulmonary disease; $\mathrm{FEV}_{1}$ : forced expiratory volume in $1 \mathrm{~s} .{ }^{\#}: \geqslant 100 \mathrm{~mL}$ decrease from baseline in trough $\mathrm{FEV}_{1 ;}{ }^{\uparrow}: \geqslant 4.0$ unit increase from baseline in SGRQ total score; ${ }^{+}: \geqslant 2.0$ unit increase from baseline in CAT score. $p<0.001$ for all comparisons.

and 3). Similar results were seen using the $\mathrm{CID}^{\mathrm{CAT}}$ definition, with FF/UMEC/VI significantly reducing CID risk by $28 \%$ and $27 \%$ at week 28 and 52, respectively, versus FF/VI, and by $23 \%$ and $22 \%$, respectively, versus $\mathrm{UMEC} / \mathrm{VI}$ (all $\mathrm{p}<0.001$ ) (figures 2 and 3 ).

FF/UMEC/VI significantly reduced the risk of all individual CID components versus FF/VI and UMEC/VI, with the greatest reduction observed for the lung function component (56\% and $52 \%$ by week 28 and 52, respectively, versus FF/VI; 34\% by both week 28 and 52 versus UMEC/VI; all p<0.001) (figure 2).

There was no concordance $($ i.e. $\kappa<0.2)$ between any of the three individual CID components at week 28 or 52 within both composite end-points in the overall study population or for any treatment arm. 

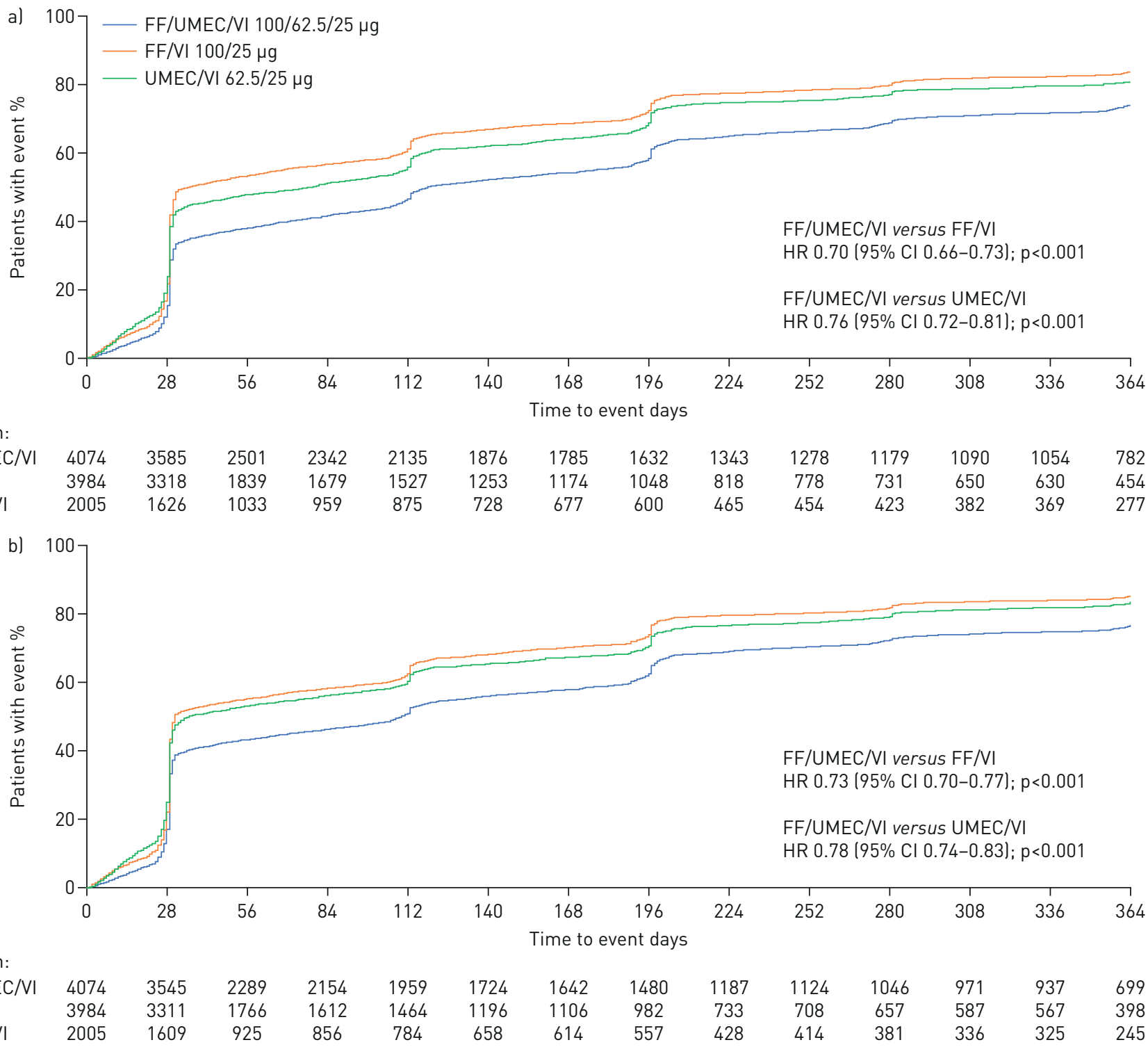

FIGURE 3 Kaplan-Meier plots of time to first clinically important deterioration (CID) event using a) the three-component definition using the St George's Respiratory Questionnaire (CID ${ }^{S G R}$ ) and b) the three-component definition using the COPD Assessment Test (CID ${ }^{C A T}$ ). COPD: chronic obstructive pulmonary disease; FF: fluticasone furoate; UMEC: umeclidinium; VI: vilanterol; HR: hazard ratio.

The comparison of health status deterioration using either SGRQ or CAT worsening showed only a weak level of concordance ( $\kappa=0.23-0.27$ and $0.29-0.30$ at week 28 and 52, respectively) (supplementary table E2).

Subgroup analysis of CID risk by week 52

Across all subgroups analysed, including different exacerbation histories, and for both $\mathrm{CID}^{\mathrm{SGRQ}}$ and $\mathrm{CID}^{\mathrm{CAT}}$, FF/UMEC/VI demonstrated significant reductions in CID risk by week 52 versus $\mathrm{FF} / \mathrm{VI}$ and UMEC/VI, with the exception of the small subgroup of patients on LAMA+LABA therapy prior to screening (8-9\% of patients). In this subgroup, FF/UMEC/VI significantly reduced CID risk versus FF/VI but not UMEC/VI $\left(\mathrm{CID}^{\mathrm{SGRQ}} 36 \%(\mathrm{p}<0.001)\right.$ and $12 \%(\mathrm{p}=0.203)$ risk reduction; $\mathrm{CID}^{\mathrm{CAT}} 28 \%(\mathrm{p}<0.001)$ and $6 \%(\mathrm{p}=0.529)$ risk reduction, respectively) (supplementary figure E3).

In the small subgroup of patients who received LAMA monotherapy prior to screening (7-9\% of patients), FF/UMEC/VI significantly reduced CID risk ( CID $^{\text {SGRQ }}$ definition) by $39 \%(p<0.001)$ and $31 \%(p=0.003)$ versus FF/VI and UMEC/VI, respectively. Similar results were seen using the $\mathrm{CID}^{\mathrm{CAT}}$ definition, with FF/UMEC/VI significantly reducing the risk of a composite CID by $43 \%(\mathrm{p}<0.001)$ and $30 \%(\mathrm{p}=0.004)$ versus $\mathrm{FF} / \mathrm{VI}$ and UMEC/VI, respectively (supplementary figure E3). 

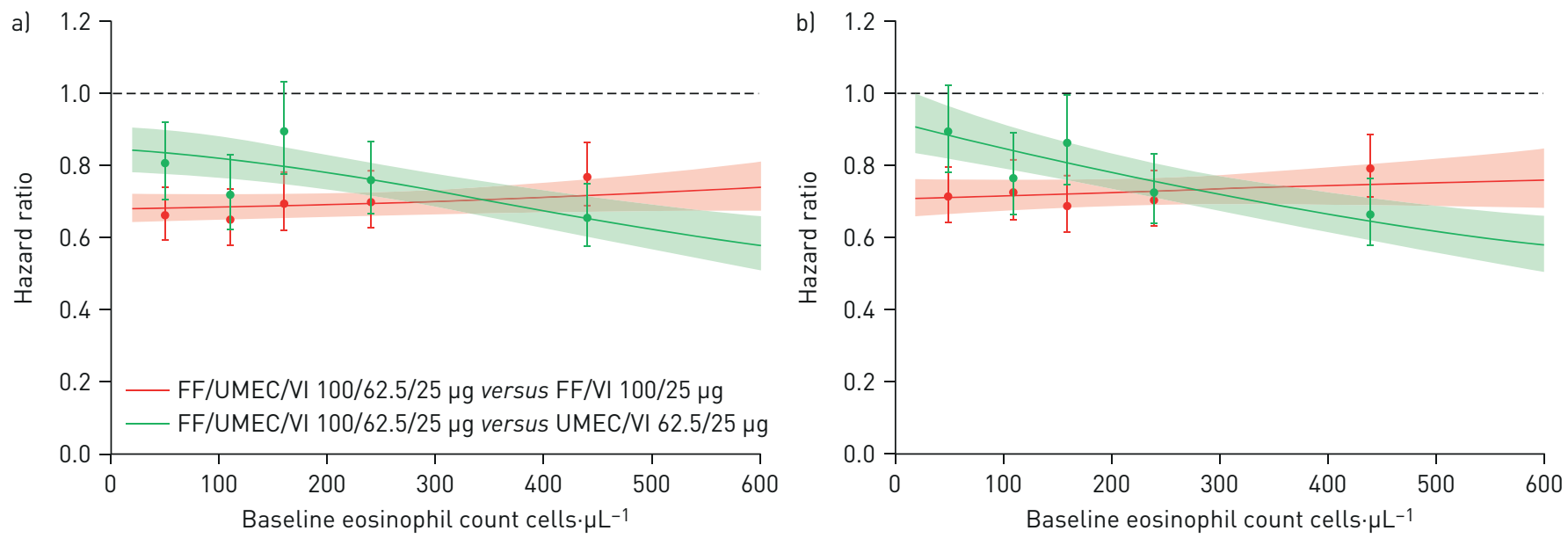

FIGURE 4 Hazard ratio (95\% CI) for a first composite clinically important deterioration (CID) up to week 52 according to baseline blood eosinophil count assessed as a continuous variable using a) the three-component definition using the St George's Respiratory Questionnaire (CID ${ }^{S G R Q}$ ) and b) the three-component definition using the COPD Assessment Test (CID ${ }^{\mathrm{CAT}}$ ). COPD: chronic obstructive pulmonary disease; FF: fluticasone furoate; UMEC: umeclidinium; VI: vilanterol. Data points and error bars denote quintiles and $95 \% \mathrm{Cl}$.

A reduction in CID risk (CID ${ }^{\mathrm{SGRQ}}$ and $\mathrm{CID}^{\mathrm{CAT}}$ definitions) by week 52 with FF/UMEC/VI versus both dual therapies was observed across the continuum of baseline blood eosinophil counts (figure 4). Treatment effect was greater at higher blood eosinophil counts for FF/UMEC/VI versus UMEC/VI. This relationship was driven by increased reduction in risk of moderate/severe exacerbation events with FF/UMEC/VI versus UMEC/VI at higher blood eosinophil counts, as there was no detectable relationship between blood eosinophil counts and reduction in the risk of lung function or health status deterioration with FF/UMEC/VI versus UMEC/VI (supplementary figure E4).

\section{Safety}

Safety data from IMPACT have been published previously [10]. The safety profile of FF/UMEC/VI was similar to FF/VI and UMEC/VI, with no new safety signals identified [10].

\section{Discussion}

This analysis of short-term disease worsening as a prognostic marker, assessed using CID status at week 28 independent of treatment, showed that patients who experience CID before week 28 have a near doubling in severe exacerbation rate during weeks 29-52 compared with CID-negative patients by week 28 . Similarly, patients with greater disease stability (CID-negative by week 28 ) had sustained clinically relevant improvements in lung function and health status at 52 weeks compared with CID-positive patients by week 28, irrespective of $\mathrm{CID}^{\mathrm{SGRQ}}$ or $\mathrm{CID}^{\mathrm{CAT}}$ definition.

Statistical significance in the mortality analysis was only achieved for the CID ${ }^{\text {CAT }}$ definition and the number of deaths was small, limiting interpretation; nevertheless, analysis of outcomes by CID status by week 28 showed that the lowest probability of all-cause mortality was consistently observed in patients free from all CID types (including lung function and health status deterioration) rather than free from exacerbation events alone. Indeed, our analysis in this population enriched for exacerbations at study entry indicates that freedom from exacerbations alone in the first 28 weeks is not a useful prognostic marker for mortality when used in isolation.

This current analysis confirms previous evidence that lung function, health status or exacerbation deteriorations are not concordant events in patients with COPD [13]. Consequently, individual CID events likely measure different forms of deterioration and sustained suboptimal responses, highlighting the heterogeneity of multiple types of worsening that occur over relatively short time periods in COPD. Using a composite end-point to capture these events appears to increase prognostic capability.

These findings are in line with those seen in TORCH [14, 15], ECLIPSE [16, 17] and FULFIL [18]. In TORCH, patients experiencing an SGRQ-defined CID in the first 6 months had a significantly greater risk of moderate/severe or severe exacerbations and mortality, and experienced sustained clinically relevant deterioration in lung function and health status over the next 30 months, compared with CID-free patients in the first 6 months [9]. Similar results were seen in ECLIPSE when comparing 3-year outcomes based on 12-month CID status [17], and a prospective analysis of FULFIL highlighted that patients CID-free by 
24 weeks had sustained improvement in lung function, health status and symptoms at 52 weeks compared with patients with a short-term CID [5]. Similarly, in the UPLIFT study comparing tiotropium versus placebo, a CID event by 6 months was associated with increased risk of subsequent exacerbation and death [6].

The prospective analysis, comparing composite worsening between treatment groups, highlighted that once-daily FF/UMEC/VI reduced the risk of composite CID and of all individual CID component events versus FF/VI and UMEC/VI. These benefits were fully apparent by week 28 for all analyses, with no increased impact at week 52. This suggests that the CID concept is well suited for detecting short-term deterioration or suboptimal treatment responses in COPD without needing a full 1-year follow-up. This is also in line with the FULFIL study results [5], demonstrating generalisability of the CID concept as a potential trial end-point. It also suggests that the benefits of optimising care with triple over dual therapy in advanced COPD occur early and go beyond exacerbation benefits. FF/UMEC/VI benefits were seen in nearly all subgroups, except in patients on LAMA+LABA therapy at baseline, where significant benefits were seen versus FF/VI but not UMEC/VI. Of interest, the greatest benefits of triple versus dual therapy were observed in patients on LAMA monotherapy at baseline. Although this finding should be investigated in further prospective studies, as only $7-9 \%$ of patients were on a LAMA at baseline, triple therapy may offer greater prevention against CID in patients with COPD who have no or limited prior exposure to combination therapies. The finding that both $\mathrm{CID}^{\mathrm{SGRQ}}$ and $\mathrm{CID}^{\mathrm{CAT}}$ definitions detected similar levels of deterioration and treatment benefits with FF/UMEC/VI versus FF/VI and UMEC/VI therapy highlights both to be potentially useful outcome measures in clinical practice. However, as the CAT instrument is easier to use and interpret than the SGRQ, this measure may have greater clinical utility in clinical practice [19]. Research into understanding the role of ICS in preventing CID event types other than exacerbations in COPD is currently limited [7, 20]. In this study, the ICS component (FF) provided short-term benefits on reducing deteriorations in lung function and health status independent of the benefit seen on preventing a first exacerbation. This finding is supported by the analysis showing each CID component was an independent marker of worsening based on $\kappa$ statistics. Surprisingly, the largest benefit of FF/UMEC/VI versus UMEC/VI was seen on reducing lung function deterioration rather than exacerbation prevention. Thus, at least in patients with symptomatic COPD and at risk of exacerbations, the ICS benefit may be broader than solely preventing exacerbations. Interestingly, in TRIBUTE, which compared the effects of alternative triple and dual regimens on CID outcomes, while significant extension in time to first composite CID with beclomethasone/glycopyrronium/formoterol versus indacaterol/glycopyrronium over 12 months was observed, when the individual components were investigated, only the SGRQ total score demonstrated significant improvement [7]. These differences seen between IMPACT and TRIBUTE may be due to a lower exacerbation risk of patients enrolled in TRIBUTE compared with IMPACT, or because the triple- and dual-therapy arms in TRIBUTE used different bronchodilator components, whereas the same LABA was used in IMPACT [10, 21].

The prevention of lung function or health status deterioration with FF/UMEC/VI versus UMEC/VI was of a similar magnitude across a range of blood eosinophil levels. In contrast, the reduction in exacerbation risk with FF/UMEC/VI versus UMEC/VI increased at higher eosinophil counts, a finding also supported by other recent trials $[10,21-25]$. These data support that important effects of ICS therapy on reducing lung function and health status worsening were likely independent of the protective effects on exacerbations. However, it is worth noting that a recent analysis of budesonide/formoterol versus formoterol studies demonstrated an association between higher eosinophil counts and greater ICS benefit on lung function and health status. As IMPACT recruited a population at risk of exacerbations, it is unclear if a similar profile of protection from disease worsening would be seen in exacerbation-free patients.

IMPACT did not include CID as a primary end-point and the 5-month follow-up period is relatively short to properly assess the risk associated with CID status at week 28 , especially regarding all-cause mortality. In line with other analyses of CID $[3,6]$, these analyses did not impute missing data. Furthermore, most of the CID components ( $\mathrm{FEV}_{1}$, SGRQ and CAT) were only assessed at study visits. While this is a limitation of all CID analyses, it also reflects clinical practice as disease progression (or treatment failure) will usually be assessed by the treating physician at scheduled visits or when key deteriorations (i.e. exacerbations) occur. Finally, findings from this analysis are reflective of a population of symptomatic patients with established exacerbation risk rather than the general COPD population. Despite these limitations, given the broad range of benefits seen with FF/UMEC/VI compared with UMEC/VI in IMPACT, further studies may be warranted to examine the benefits of add-on ICS in preventing CID in patients with less advanced disease.

\section{Conclusions}

The benefits of treatment optimisation to prevent short-term CID events are likely to reduce future risks of exacerbations requiring hospitalisation and all-cause mortality. In addition, once-daily FF/UMEC/VI 
reduced the risk of CID events versus FF/VI and UMEC/VI, demonstrating a consistent benefit across most patient types over short time periods for adding ICS or intensifying bronchodilation in the IMPACT trial population.

Acknowledgements: Editorial support (in the form of writing assistance, assembling figures, collating author comments, grammatical editing and referencing) was provided by Philip Chapman at Fishawack Indicia (Knutsford, UK). D. Singh is supported by the National Institute for Health Research Manchester Biomedical Research Centre.

Author contributions: All authors meet criteria for authorship as recommended by the International Committee of Medical Journal Editors, take responsibility for the integrity of the complete work, contributed to the writing and reviewing of the manuscript, and have given final approval for the version to be published. All authors had full access to the data in this study, and take complete responsibility for the integrity of the data and accuracy of the data analysis. All authors contributed to data analysis and interpretation. D.A. Lipson and I.P. Naya were involved in the development and design of the study. G.J. Criner, M.T. Dransfield and D.M.G. Halpin were involved in the acquisition of the data.

Conflict of interest: M.K. Han personal fees from AstraZeneca, Boehringer Ingelheim and GlaxoSmithKline, research support from Novartis and Sunovion, and personal fees from Mylan, Merck and Verona, outside the submitted work. G.J. Criner personal fees from Almirall, AstraZeneca, Boehringer Ingelheim, Chiesi, CSA Medical, Eolo Medical and GlaxoSmithKline, and ownership interest in HGE Health Care Solutions, and personal fees from Novartis, Nuvaira, Olympus, Pulmonx, Verona, Amgen, Broncus Medical, Gala Therapeutics, Helios Medical, Merck, Medtronic, Mereo BioPharma, NGM Biopharmaceuticals, Philips Respironics, Respivant Sciences and The Implementation Group, outside the submitted work. M.T. Dransfield grants from the Dept of Defense, personal fees and other support from Boehringer Ingelheim and GlaxoSmithKline, other support from Novartis, personal fees and other support from AstraZeneca, other support from Yungjin, personal fees and other support from PneumRx/BTG, other support from Pulmonx, personal fees from Genentech, other support from Boston Scientific, personal fees from Quark Pharmaceuticals, grants from $\mathrm{NIH}$, personal fees from Mereo, and grants from the American Lung Association and the NIH, outside the submitted work. D.M.G. Halpin reports personal fees from AstraZeneca, personal fees and nonfinancial support from Boehringer Ingelheim, personal fees from Chiesi, personal fees and nonfinancial support from GlaxoSmithKline, and personal fees from Novartis, Pfizer and Sanofi, outside the submitted work. C.E. Jones is an employee of and holds shares/options in GlaxoSmithKline, outside the submitted work. S. Kilbride is an employee of and holds shares/options in GlaxoSmithKline, outside the submitted work. P. Lange personal fees from AstraZeneca, Boehringer Ingelheim and Chiesi, and grants and personal fees from GlaxoSmithKline, outside the submitted work. S. Lettis is an employee of and holds shares/options in GlaxoSmithKline outside the submitted work. D.A. Lipson is an employee of and holds shares/ options in GlaxoSmithKline outside the submitted work. D.A. Lomas reports grants from GlaxoSmithKline and personal fees from Grifols, outside the submitted work. N. Martin is an employee of and holds shares/options in GlaxoSmithKline, outside the submitted work. F.J. Martinez reports personal fees, nonfinancial support and other support from AstraZeneca and Boehringer Ingelheim, nonfinancial support and other support from ProterrixBio, personal fees from Columbia University, personal fees and nonfinancial support from Genentech, GlaxoSmithKline and Inova Fairfax Health System, personal fees from MD Magazine and Methodist Hospital Brooklyn, personal fees and nonfinancial support from Miller Communications, the National Association for Continuing Education and Novartis, personal fees from New York University, personal fees and nonfinancial support from Pearl Pharmaceuticals, PeerView Communications, Prime Communications, the Puerto Rican Respiratory Society, Chiesi, Sunovion and Theravance, personal fees from UpToDate and WebMD/MedScape, other support from Afferent/Merck, nonfinancial support from Gilead and Nitto, personal fees and other support from Patara/Respivant, personal fees and nonfinancial support from Potomac, other support from Biogen, personal fees and nonfinancial support from the University of Alabama Birmingham, other support from Veracyte, nonfinancial support from Zambon, personal fees from the American Thoracic Society, grants from the NIH, personal fees and nonfinancial support from the Physicians Education Resource, personal fees from Rockpointe, other support from Prometic, personal fees from Rare Disease Healthcare Communications, other support from Bayer and Bridge Biotherapeutics, personal fees and nonfinancial support from the Canadian Respiratory Network, other support from ProMedior, personal fees and nonfinancial support from Teva, personal fees from the France Foundation, personal fees and nonfinancial support from Dartmouth, other support from Gala, and personal fees from the Physicians Education Resource, outside the submitted work. R.A. Wise reports grants and personal fees from AstraZeneca/Medimmune/Pearl and Boehringer Ingelheim, personal fees from Contrafect, Pulmonx, Roche, Spiration and Sunovion, grants from Pearl Therapeutics, personal fees from Merck, Circassia, Pneuma, Verona, Mylan/Theravance and Propeller Health, grants from Sanofi-Aventis, personal fees from AbbVie, and grants and personal fees from GSK, outside the submitted work. I.P. Naya holds shares/options in GlaxoSmithKline, outside the submitted work. D. Singh reports grants and personal fees from AstraZeneca, Boehringer Ingelheim and Chiesi, personal fees from Cipla and Genentech, grants and personal fees from Glenmark, personal fees from GlaxoSmithKline, grants and personal fees from Menarini and Mundipharma, personal fees from Peptinnovate, and grants and personal fees from Pfizer, Pulmatrix, Theravance and Verona, outside the submitted work.

Support statement: This study was funded by GlaxoSmithKline. The funders of the study had a role in the study design, data analysis, data interpretation, and writing of the report. Funding information for this article has been deposited with the Crossref Funder Registry.

\section{References}

1 Global Initiative for Chronic Obstructive Lung Disease. Global Strategy for the Diagnosis, Management, and Prevention of Chronic Obstructive Pulmonary Disease. 2020. www.goldcopd.org/wp-content/uploads/2019/11/ GOLD-2020-REPORT-ver1.0wms.pdf Date last accessed: December 23, 2020.

2 Singh D, Agusti A, Anzueto A, et al. Global Strategy for the Diagnosis, Management, and Prevention of Chronic Obstructive Lung Disease: the GOLD science committee report 2019. Eur Respir J 2019; 53: 1900164.

3 Singh D, Maleki-Yazdi MR, Tombs L, et al. Prevention of clinically important deteriorations in COPD with umeclidinium/vilanterol. Int J Chron Obstruct Pulmon Dis 2016; 11: 1413-1424. 
4 Anzueto AR, Vogelmeier CF, Kostikas K, et al. The effect of indacaterol/glycopyrronium versus tiotropium or salmeterol/fluticasone on the prevention of clinically important deterioration in COPD. Int J Chron Obstruct Pulmon Dis 2017; 12: 1325-1337.

5 Naya I, Compton C, Ismaila AS, et al. Preventing clinically important deterioration with single-inhaler triple therapy in COPD. ERJ Open Res 2018; 4: 00047-2018.

6 Rabe KF, Halpin DMG, Han MK, et al. Composite endpoints in COPD: clinically important deterioration in the UPLIFT trial. Respir Res 2020; 21: 177.

7 Singh D, Fabbri LM, Vezzoli S, et al. Extrafine triple therapy delays COPD clinically important deterioration $v$ s ICS/LABA, LAMA, or LABA/LAMA. Int J Chron Obstruct Pulmon Dis 2019; 14: 531-546.

8 Maltais F, Bjermer L, Kerwin EM, et al. Efficacy of umeclidinium/vilanterol versus umeclidinium and salmeterol monotherapies in symptomatic patients with COPD not receiving inhaled corticosteroids: the EMAX randomised trial. Respir Res 2019; 20: 238.

9 Naya IP, Tombs L, Muellerova $\mathrm{H}$, et al. Long-term outcomes following first short-term clinically important deterioration in COPD. Respir Res 2018; 19: 222.

10 Lipson DA, Barnhart F, Brealey N, et al. Once-daily single-inhaler triple versus dual therapy in patients with COPD. N Engl J Med 2018; 378: 1671-1680.

11 Jones PW, Beeh KM, Chapman KR, et al. Minimal clinically important differences in pharmacological trials. Am J Respir Crit Care Med 2014; 189: 250-255.

12 Kon SS, Canavan JL, Jones SE, et al. Minimum clinically important difference for the COPD Assessment Test: a prospective analysis. Lancet Respir Med 2014; 2: 195-203.

13 Anzueto AR, Kostikas K, Mezzi K, et al. Indacaterol/glycopyrronium versus salmeterol/fluticasone in the prevention of clinically important deterioration in COPD: results from the FLAME study. Respir Res 2018; 19: 121.

14 Calverley PM, Anderson JA, Celli B, et al. Salmeterol and fluticasone propionate and survival in chronic obstructive pulmonary disease. N Engl J Med 2007; 356: 775-789.

15 The TORCH Study Group. The TORCH (TOwards a Revolution in COPD Health) survival study protocol. Eur Respir J 2004; 24: 206-210.

16 Agusti A, Calverley PM, Celli B, et al. Characterisation of COPD heterogeneity in the ECLIPSE cohort. Respir Res 2010; 11: 122.

17 Vestbo J, Anderson W, Coxson HO, et al. Evaluation of COPD Longitudinally to Identify Predictive Surrogate End-points (ECLIPSE). Eur Respir J 2008; 31: 869-873.

18 Lipson DA, Barnacle H, Birk R, et al. FULFIL trial: once-daily triple therapy for patients with chronic obstructive pulmonary disease. Am J Respir Crit Care Med 2017; 196: 438-446.

19 Jones PW, Harding G, Berry P, et al. Development and first validation of the COPD Assessment Test. Eur Respir J 2009; 34: 648-654.

20 Bafadhel M, Singh D, Jenkins C, et al. Reduced risk of clinically important deteriorations by ICS in COPD is eosinophil dependent: a pooled post-hoc analysis. Respir Res 2020; 21: 17.

21 Papi A, Vestbo J, Fabbri L, et al. Extrafine inhaled triple therapy versus dual bronchodilator therapy in chronic obstructive pulmonary disease (TRIBUTE): a double-blind, parallel group, randomised controlled trial. Lancet 2018; 391: 1076-1084.

22 Bafadhel M, Peterson S, De Blas MA, et al. Predictors of exacerbation risk and response to budesonide in patients with chronic obstructive pulmonary disease: a post-hoc analysis of three randomised trials. Lancet Respir Med 2018; 6: 117-126.

23 Pascoe S, Locantore N, Dransfield MT, et al. Blood eosinophil counts, exacerbations, and response to the addition of inhaled fluticasone furoate to vilanterol in patients with chronic obstructive pulmonary disease: a secondary analysis of data from two parallel randomised controlled trials. Lancet Respir Med 2015; 3: 435-442.

24 Pascoe S, Barnes N, Brusselle G, et al. Blood eosinophils and treatment response with triple and dual combination therapy in chronic obstructive pulmonary disease: analysis of the IMPACT trial. Lancet Respir Med 2019; 7 : 745-756.

25 Vestbo J, Papi A, Corradi M, et al. Single inhaler extrafine triple therapy versus long-acting muscarinic antagonist therapy for chronic obstructive pulmonary disease (TRINITY): a double-blind, parallel group, randomised controlled trial. Lancet 2017; 389: 1919-1929.

26 Jones JP. St. George’s Respiratory Questionnaire: MCID. COPD 2005; 2: 75-79. 